\title{
Prevalence of menstrual disorders and its related factors in the students of Kurdistan University Of Medical Science in 2018
}

Roonak Shahoei ${ }^{1}$, Bijan Nouri ${ }^{2}$, Nazila Darvishi ${ }^{3}$, Khadijeh Rezaie ${ }^{4}$, Hiva Zandi ${ }^{5}$, Sheno Bayazidi ${ }^{6}$, Fatemeh Khezrnezhad $^{7}$

1. Associate Professor of Midwifery Education, Department of Midwifery, School of Nursing and Midwifery, Kurdistan University of Medical Sciences, Sanandaj, Iran. ORCID ID: 0000-0002-5509-4257

2. Assistant Professor of Social Determinants of Health Research Center, Research Institute for Health Development, Kurdistan University of Medical Sciences, Sanandaj, Iran. ORCID ID: 0000-0002-2932-5058

3. MD, PhD of Nutrition, Sanandaj, Iran. ORCID ID: 0000-0003-1597-0838

4. Midwifery student, Student Research Committee, Kurdistan University of Medical Sciences, Sanandaj, Iran. ORCID ID:0000-0002-2094-6966

5. Public health student, Student Research Committee, Kurdistan University of Medical Sciences, Sanandaj, Iran. ORCID ID:0000-0002-7369-2939

6. Msc student of Epidemiology, Student Research Committee, Iran University of Medical Sciences, Tehran, Iran. ORCID ID: 0000-0001-6167-3688

7. Public health student, Student Research Committee, Kurdistan University of Medical Sciences, Sanandaj, Iran., (Corresponding Author), Tel: 988138398609, Email: f.xezrnezhad72@gmail.com, ORCID ID:0000-0003-1378-9613

\section{ABSTRACT}

Background and Aim: Menstrual disorders are one of the most common complaints of women, they have a wide range including delayed periods to painful periods. They are common and benign and can lead to decreased quality of life. The aim of this study was to determine the prevalence of menstrual disorders and its related factors in the students of Kurdistan University of Medical Sciences.

Material and Method: This was a descriptive-analytical study. The statistical population included students of Kurdistan University of Medical Sciences. We used cluster sampling and selected 300 students. Research tools included a questionnaire consisted of 10 demographic questions, 26 main questions and a chart for measurement of the amount of menstrual bleeding in a period. Data were introduced into STATA 12 and SPSS 22 softwares and analyzed by independent t-test, $\chi 2$ and Fisher's test.

Results: The prevalence of menstrual disorders in the study population was $15.3 \%$. The most and least common disorders were dysmenorrhea and hypomenorrhea. Dysmenorrhea had significant relationships with, body mass index $(\mathrm{P}=0.044)$ and age $(\mathrm{P}=0.021)$. There was also a significant relationship between marital status and mastalgia $(\mathrm{P}=0.015)$. We found a significant relationship between menorrhagia and age $(\mathrm{P}=0.026)$, and also between hypermenorrhea and age $(\mathrm{P}=0.045)$.

Conclusion: The results of this study showed presence of at least one type of menstrual disorder among the students of Kurdistan University of Medical Sciences as an example of society, which is a threat to the individual and social life of women and girls.

Keywords: Menstrual Disorders, Related Factors, Student, Kurdistan

How to cite the article: Roonak Shahoei, Bijan Nouri, Nazila Darvishi, Khadijeh Rezaie, Hiva Zandi, Sheno Bayazidi, Fatemeh Khezrnezhad. Prevalence of the Menstrual Disorders and its Related Factors in Students of Kurdistan University of Medical Sciences in 2018.S JKU. 2020;25(4):31-41.

Copyright (C) 2018 the Author (s). Published by Kurdistan University of Medical Sciences. This is an open access article distributed under the terms of the Creative Commons Attribution-Non Commercial License 4.0 (CCBYNC), where it is permissible to download, share, remix, transform, and buildup the work provided it is properly cited. The work cannot be used commercially without permission from the journal 


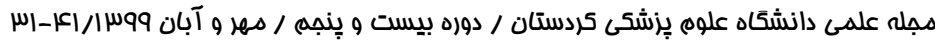

\section{شيوع اختلالات قاعدكى و عوامل مرتبط با آن در دانشجويان دانشكاه علوم يزشكى كردستان در سالrqri}

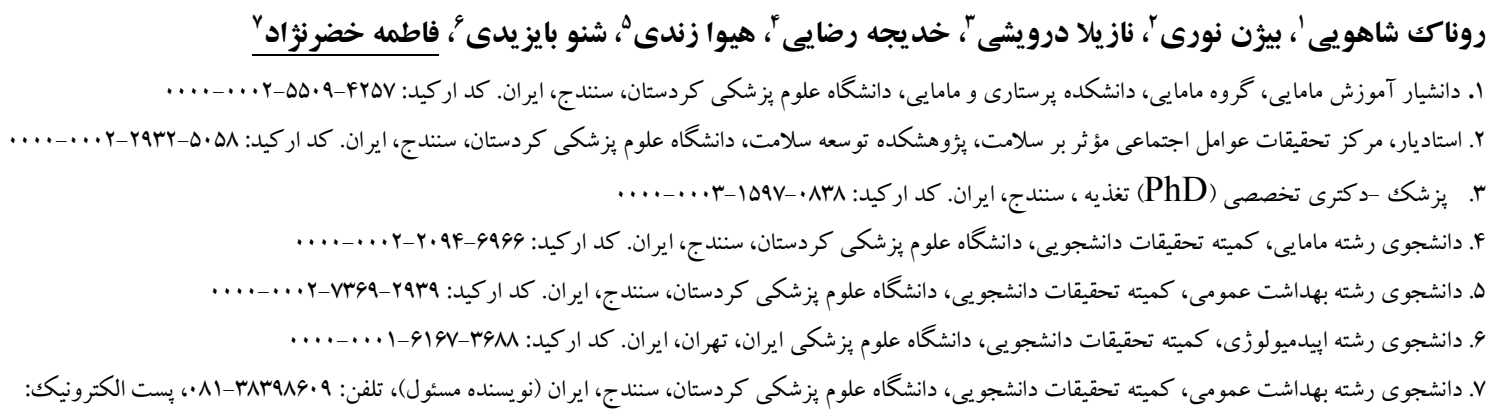
…_...r-IrVA-q91r: f.xezrnezhad72@gmail.com

جكيله

زمينه و هدف: اختلالات و مشكلات قاعدكى از شايع ترين شكايات زنان مىباشد كه از سيكلهاى به تعويق افتاده تا سيكلهاى

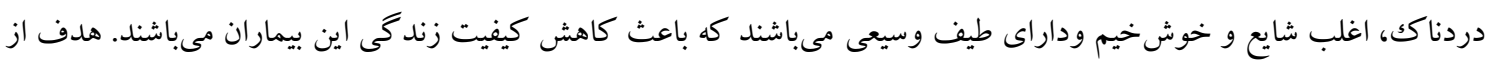

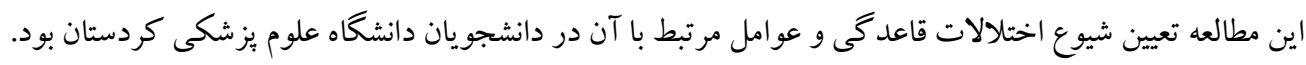

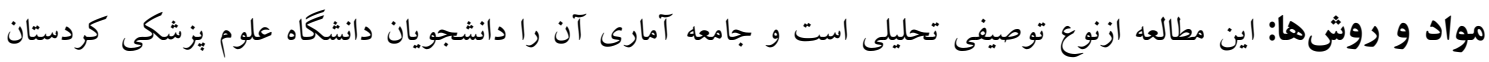

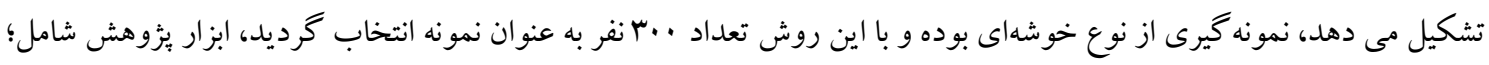

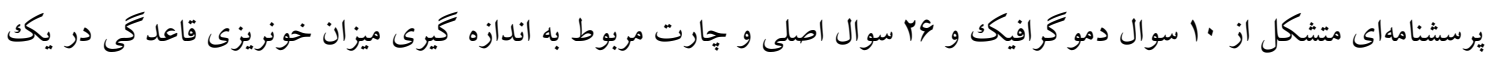

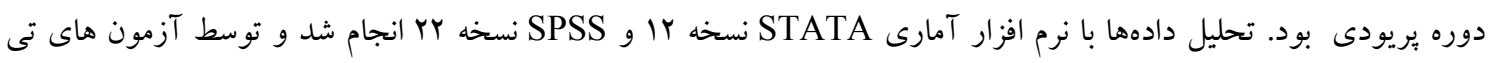
مستقل، بح و Fisher-Test تجزيه و تحليل گرديد.

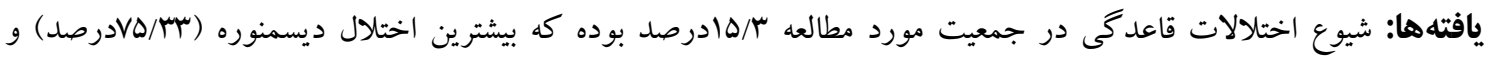

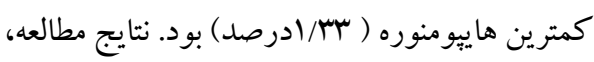

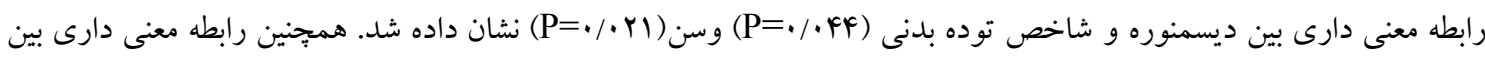

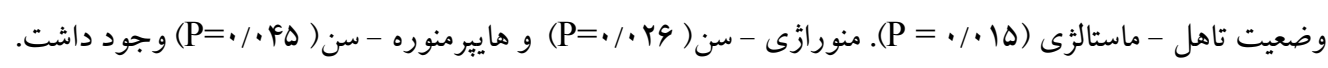

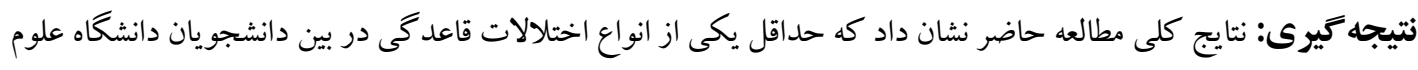

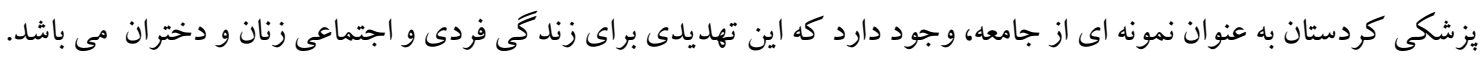
كلمات كليدى: اختلالات قاعدگى، عوامل مر تبط، دانشجو، كردستان

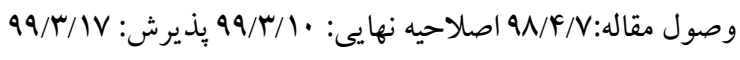


وجود ديسمنوره يكى از عوامل اصلى مختل كنندهى كيفيت

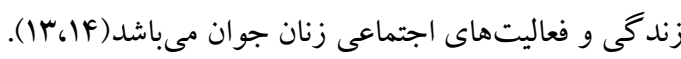
درد قاعدىى در تعدادى از زنان منجر به اختلال در انجام رهام امور از جمله خانهدارى، دشوارى در انجام امور شغلى و

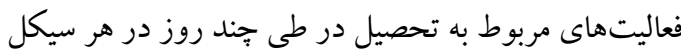

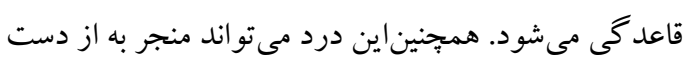
رفتن زمان مطالعه و تحصيل و كار در زنان به خصوص در در

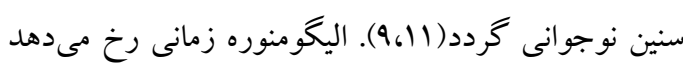

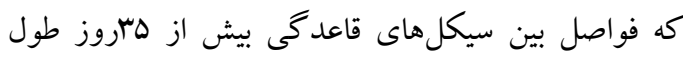
بكشديا تعداد سيكلها V-ه بار در يكك سال باشد. در دهـ -

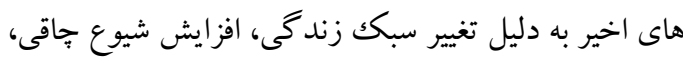

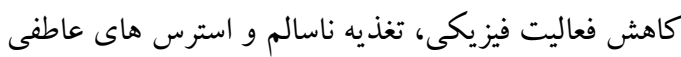

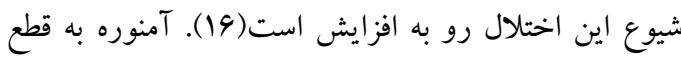
كامل قاعدگى بيش از شش ماه در زنانى كه قاعدكى إنى

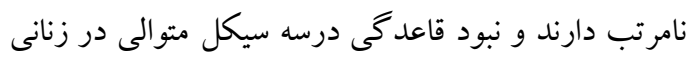

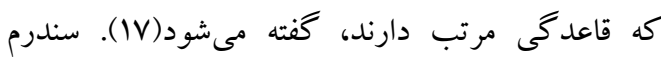
تخمدان يلى كيستيك شايع ترين اختلال غدد داخلى زئل زنان در دوران بارورى است. تظاهرات بالينى اين سندرم مىتواند بسيار مختلف باشد به همين دليل تعريف واحدى از PCOS وجود ندارد(1)). منورازى به معناى از دست دادن هشتاد سى سى خون در هر سيكل قاعدگى است و و شايعترين دليل كم خونى فقر آهن در زنان مىباشد(11).

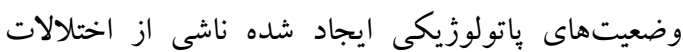

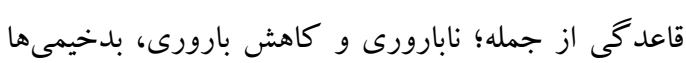

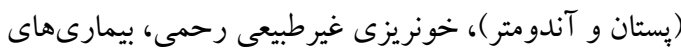

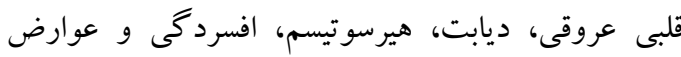

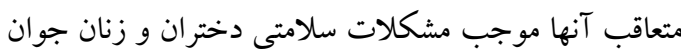
وكاهش كيفيت زندگى آنها مى گردد. كه تشخيص و و

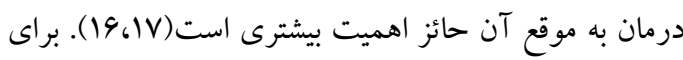

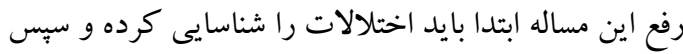

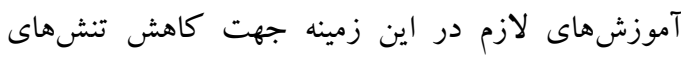

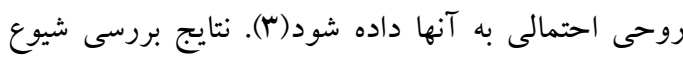

مقدمه جرخه قاعدگى شامل فعاليت و تعامل هورمونهايى است

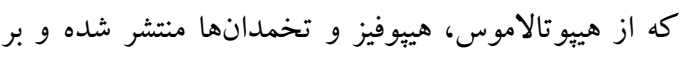

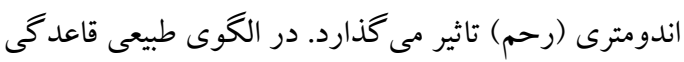

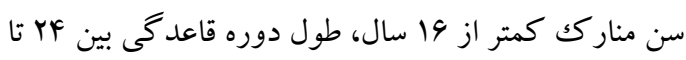

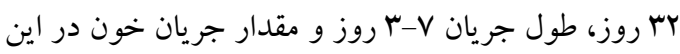

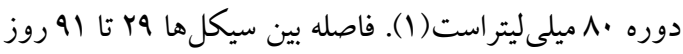

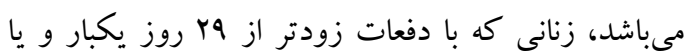

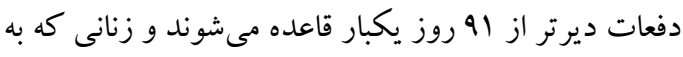
طور ثابت V روز يا بيشتر خونريزى دارند ويا ميزان

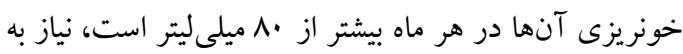

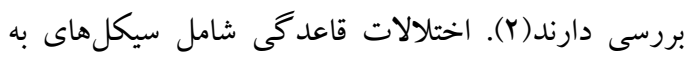

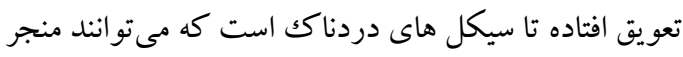

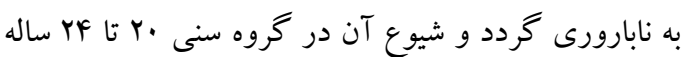

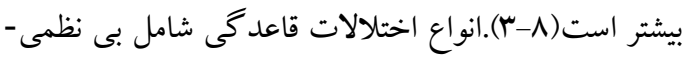
هاى قاعدكى (طول يا مدت زمان)، هايِرمنوره، هاييو منوره،

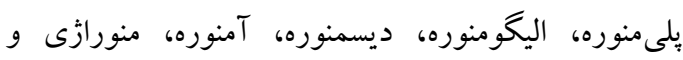

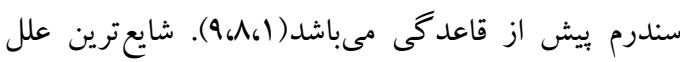

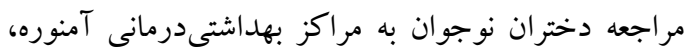

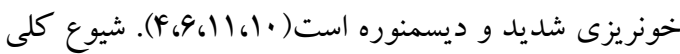

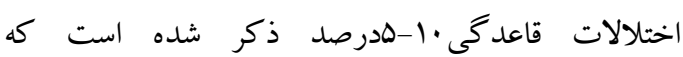
دره لدرصد دختران الكوى طبيعى قاعدگى در دو سال اول

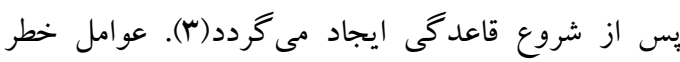
قاعدگى دردناك شامل: سن كمتر از بيست سال، رزيمهاى

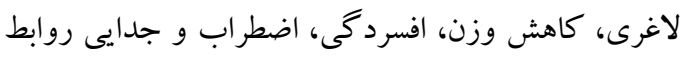

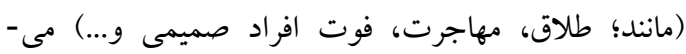

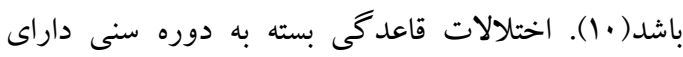

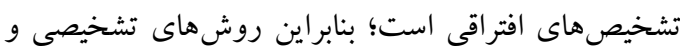

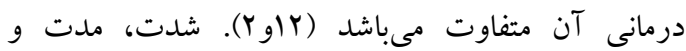
فركانس تمرين ورزشى، دريافت انرزى كمتر و نوع إنى

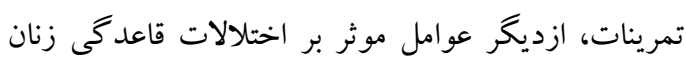

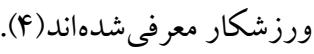




$$
n=\left(\begin{array}{c}
Z_{1-\frac{\alpha}{2}} \\
d
\end{array}\right)^{2} p \times\left(\begin{array}{ll}
1 & p
\end{array}\right)
$$

برسشنامه شامل •1سوال در مورد خصوصيات دمو گرافيك: (سن، وضعيت تاهل، BMI ، محل سكونت، مقطع تحصيلى و رشته تحصيلى) و Y4 سوال اصلى شامل سوالات مربوط به اختلالات قاعدگى (ديسمنوره، بلى

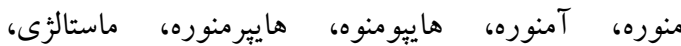
اليكومنوره، منورازى، منومترورازى، PCOD، سابقه عفونت تناسلى) و جارت مربوط به اندازه گيرى ميزان خونريزى قاعدگى در يك دوره بريودى بود براى تاييد

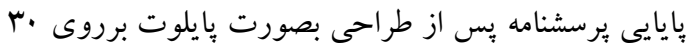
نفر از نمونهها، از طريق آلفاى كرونباخ \&^/. تاييد شد. همجِنين روايى برسشنامه نيز توسط دو نفر متخصص زنان تاييد كرديد. در نهايت يرسشنامه توسط محققان (دو نفر كارشناس بهداشت عمومى و مامايى) به كلاس ها برده شد و يس از توجيه مخاطبين بر و جمع آورى گرديد. براى تعيين ميزان حجم خونريزى يكك دوره بريودى نيز بس از كسب رضايت شفاهى از دانشجويان جارت اندازه گيرى ميزان خونريزى در اختياردانشجويان قرار گرفت تا درطول يك دوره بريودى به صورت دقيق ميزان خونريزى شان را اندازه كرفته و ارجاع دهند. اطلاعات جمع آورى شده وارد نرم فزار آمارى STATA نسخه r 1 و SPSS نسخه r ش شد و توسط آزمون هاى تى مستقل، جأ و Fisher-Test تجزيه و تحليل كرديد. (جارت تعيين Assessment Chart اختلالات قاعدگى)؛ داراى ·1 ستون روزانه و سه سطر مقدار خون روى نوارهاى بهداشتى ( به صورت كم، متوسط

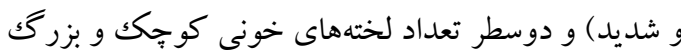
مىباشد، هر فرد با خط جوب ياعدد مشخص مى كند كه در هرروز از يريود خود جهه تعداد نوار بهداشتى و به جه مقدار خون (كم، متوسط و شديد) را مصرف مى كند و اينكه در طول بريودىاش جهه تعداد لخته خونى و باجه اندازهاى را
اختلالات قاعدگى در دانش آموزان دوره راهنمايى و دبيرستان زنجان نشان داد كه MV.V درصد از اين جمعيت داراى اختلالات قاعدگى بودند(19). به علت شرايط سنى

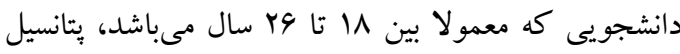
ازدواج و بارورى آنها بالاست، از طرفى زنان غالبا قاعدگى را دليل سلامت بارورى خود مىدانند و اختلال آن باعث حساسيت آنها مىشود، لذا بررسى وضعيت كلى اين اختلالات در دانشجويان و انعكاس آن مىتواند بر كاهش

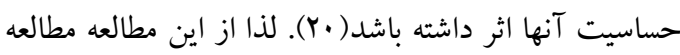
تعيين شيوع اختلالات قاعدگى و عوامل مرتبط با آن در دانشجويان دانشكاه علوم يزشكى كردستان مىباشد..

\section{مواد و روشها}

اين مطالعه توصيفى-تحليلى از نوع مقطعى مىباشد. جامعه آمارى و معيار رود شامل؛ كليه دانشجويان دختر در كليه ترمهاى تحصيلى سال IMqV دانشگاه علوم يزشكى كردستان مشغول به تحصيل كه مايل به شركت در مطالعه بودند را تشكيل داد. معيار خروج: شامل، افرادى كه مايل به شركت در تحقيق نبودند، دانشجويان باردار، دانشجويان رزيدنت (به علت عدم دسترسى)، دانشجويان داراى مشكلات تيروئيدى و يا ميوم (فيبروم) (به دليل اينكه موجب بى نظمى قاعدگى و خونريزى مىشوند) بودند. در ابتدا با دانشجويان هماهنخى شده و توضيحات لازم ارائه داده شد همجنين اين اطمينان به آنها داده شده كه اطلاعاتشان محرمانه خواهد ماند. روش نمونه صورت خوشهاى با تخصيص مناسب بود. دانشگاه علوم

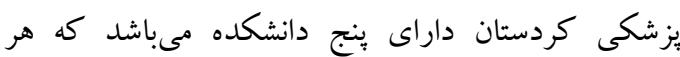
دانشكده يكك خوشه محسوب شد. با در نظر كرفتن شيوع اختلالات قاعدگى متوسط (هاץ/F درصد) و سطح اطمينان ه9 درصد، و خطاى لهدرصد، حجم نمونه مورد نياز جهت تحقق اهداف مطالعه با استفاده از رابطه زير و براساس مطالعه مشابه برابر ..r.نفر بود(r). 
ساكنين خوابكاهها (

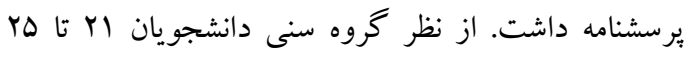

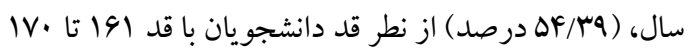

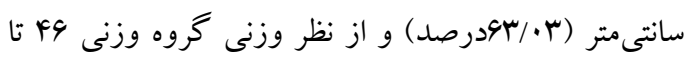

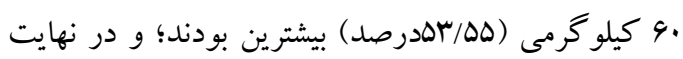
دروصد دانشجويان داراى BMI/DV

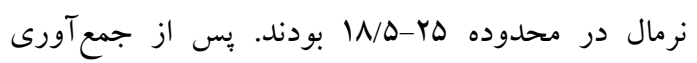

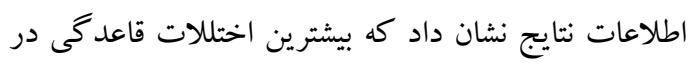

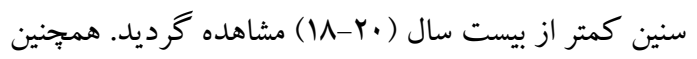

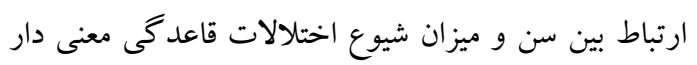

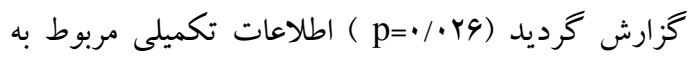

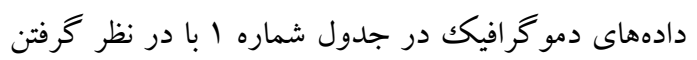
ريزش آورده شده است.
داشته است. امتياز نهايى هرفرد با توجه به ضريبهاى مشخص شده محاسبه شد (به اين ترتيب كه براى نوار

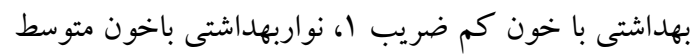

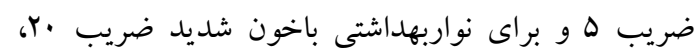

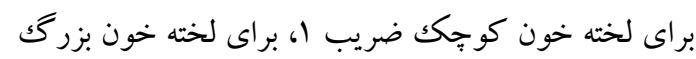

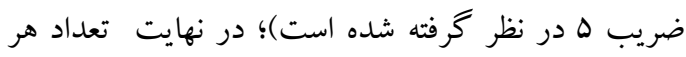

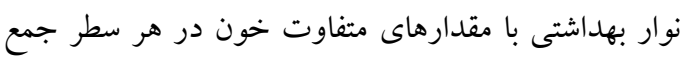

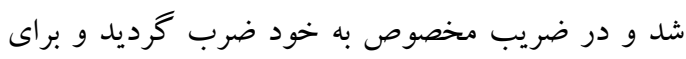
لختهاى خونى نيز به همان صورت انجام شد و و كل برد برد

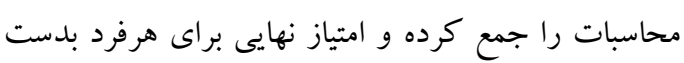
Tمد T T

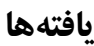

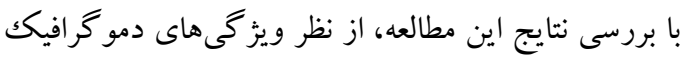

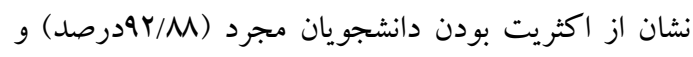

جدول ا. مشخصات دموكر افيك جمعيت مورد مطالعه

\begin{tabular}{|c|c|c|c|}
\hline (درصد) & دموكر افيك & (درصد) & دموكر افيك \\
\hline & وزن & & سن \\
\hline $\mid r(F / 9 \mid)$ & $<r_{\Delta}$ & $11 \cdot(r 4 / 9)$ & $<=r$. \\
\hline$|\Delta|(\Delta r / \Delta \Delta)$ & k9-9. & $1 \Delta \Delta(\Delta F / r q)$ & rI-ro \\
\hline $1 . \Delta(r V / Y r)$ & 91-VD & $q(r / 1 q)$ & $r \varphi-r$. \\
\hline $\operatorname{Ir}(F / r q)$ & vy-q. & $11(r / \wedge 9)$ & $>=r 1$ \\
\hline \multirow[t]{2}{*}{$1(\cdot / r \Delta)$} & $>q$. & & \\
\hline & BMI & & قد \\
\hline$r \Delta(|Y / F|)$ & $<1 N / \Delta$ & $F(1 / 4-1)$ & $14 \cdot-10$. \\
\hline $199(V \cdot / \Delta V)$ & $\mid N / \Delta-Y \Delta$ & $V r(r \Delta / V \cdot)$ & $101-19$. \\
\hline $\operatorname{er}(\mid F / \wedge q)$ & rq-r. & $\operatorname{lV}(9 \% / . r)$ & $|9|-1 V$. \\
\hline \multirow[t]{2}{*}{$\Delta(I / V V)$} & M-IM & $r \wedge(9 / \wedge 9)$ & $|V|-\mid \Lambda$. \\
\hline & محل سكونت & & وضعيت تاهل \\
\hline $\operatorname{LPF}(\Delta V / G \Lambda)$ & خوابكاه & Y $91(9 \mathrm{Q} / \mathrm{AM})$ & مجرد \\
\hline$\| r(F r / r r)$ & منزل & $r \cdot(I Y / V)$ & متاهل \\
\hline
\end{tabular}

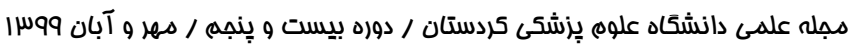


خونريزى ه ميلى ليتر بود كه ميانگين امتياز اندازه خونريزى

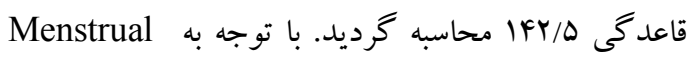
Assessment Chart محاسبات انجام شده، امتياز نهايى هر فرد محاسبه شده است. بيشترين مدت خونريزى قاعدگى · الروز و كمترين مدت 1 روز بود و ميانگين مدت خونريزى قاعدگى بر/ه روز كز ارش شد.
همجنين ميزان شيوع ابتلا به عفونت تناسلى و ادرارى rV rادرصد زارش شد. طبق يافتهاى يزوهش (جدول شماره Y) ديسمنوره با س//VDدرصد داراى بيشترين شيوع، و كمترين شيوع مربوط به هاييومنوره با سم/ا درصد بود. براى اختلال آمنوره موردى يافت نشد. نتايج نشان داد كه كمترين سن شروع قاعدگى · ل سال و بيشترين سن \1 سال و ميانگين سن شروع قاعدگى افراد ساسال بود. بيشترين ميزان خونريزى قاعدكى 4 FA ميلىليتر بود و كمترين ميزان

\begin{tabular}{|c|c|c|}
\hline درصد & تعداد & انواع اختلال \\
\hline$\Delta$ & 10 & يلى منوره \\
\hline 1. & r. & ماستالزى \\
\hline$V \Delta / r r$ & r94 & ديسمنوره \\
\hline $1 / r$ & f & هايِومنوره \\
\hline 11 & r & اليكومنوره \\
\hline$r \cdot / r$ & 91 & منورازى \\
\hline$r / 9 V$ & $\wedge$ & مونومترورازى \\
\hline ir & rq & هايِرمنوره \\
\hline$r|/ r|$ & 94 & PCOS \\
\hline . & . & آمنوره \\
\hline rV & vi & ابتلا به عفونت تناسلى و ادرارى \\
\hline
\end{tabular}


بارامترها ارتباط معنى دارى با شيوع اختلالات مختلف

قاعدگى نداشتند همجِنين رابطه معنىدارى بين منورازى و

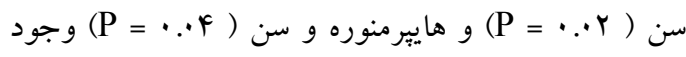

داشت. از بين افرادى كه داراى الكوى طبيعى قاعدگى

بودند Y د درصد براى منظم شدن دوره قاعد گى خود دارو

$$
\text { مصرف مى كردند. }
$$

معنىدار بودن پارامترها با شيوع اختلالات قاعدگى در جدول شماره r آورده شده است؛ همانطور كه مشاهده مىشود، ارتباط معنىدارى بين ميزان شيوع اختلالات قاعدگى با بارامترهاى وضعيت تاهل، BMI، سن وجود داشت. رابطه معنىدارى بين وضعيت تاهل و ماستالزى

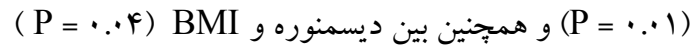
و ديسمنوره و سن( Y..・

جدول r. ارتباط بين متغيرها و اختلالات قاعدكى در دانشجويان دانشكاه علوم يزشكى كردستان

\begin{tabular}{|c|c|c|c|c|c|c|c|c|c|}
\hline & & & & $P$ value & & & & & \\
\hline PCOS & هايير منوره & منومترورازى & منورازى & اليكومنوره & هايِيومنوره & ديسمنوره & ماستالزى & يلى منوره & متغير \\
\hline . /1Ts & $\cdot / 491$ & $\cdot / 491$ &.$/ 194$ &.$/ 101$ & $\cdot / A \vee q$ &.$/ 99 \mathrm{~V}$ & $\cdot / 114$ & $\cdot / F A I$ & دانشكده \\
\hline •/Trr & $.19 \mathrm{YV}$ & .1 .09 & . IMF & $\cdot / \Delta \Lambda$. & $\cdot / \mathrm{v} \cdot \cdot$ & .1 .09 &.$/ 491$ & $\cdot / T V$ & مقطع \\
\hline.$/ 91$. &.$/ 91$. &.$/ 109$ &.$/ 019$ & . / FAY & $\cdot / 971$ & .194. & $\cdot / \Delta r V$ & . /Frk & معدل \\
\hline - / $\Delta Q$ &.$/ . \Delta 1$ & . /VYr & $\cdot / \cdot V F$ & . /arb & $\cdot / \Delta \wedge F$ &.$/ 09$. &.$/ 91 f$ & .1991 & وزن \\
\hline.$/ 949$ & $\cdot / \Delta F A$ & $1 / \cdots$ & & $\cdot / r_{H}$ & - /TAG & $\cdot / r \Delta F$ & - /AY. & - / FAY & قد \\
\hline - ItPG & $\cdot / \cdot 11$ & $\cdot / r 99$ & $\cdot /$ TIF &.$/ 194$ &.$/ 1 \Delta \Delta$ & $.1 \cdot F F$ &.$/ 1 \Delta \Delta$ & •/VMr & نمايه توده \\
\hline - / $\Delta r q$ &.$/ .4 \Delta$ & $\cdot / \Delta F a$ &.$/ . Y 4$ & $\cdot / r V \Delta$ & $\cdot / 99$ & $\cdot / \cdot r \mid$ & $\cdot / 491$ & $\cdot / 111$ & سن \\
\hline $1 / \cdots$ & $\cdot /$ MV & $1 / \cdots$ &.$/ 119$ & $\cdot / v \cdot q$ &.$/ 99$ & $\cdot / \cdot \wedge \mathrm{V}$ & $.1 \cdot 10$ &.$/ 99$ & وضعيت \\
\hline • / fru & $\cdot / / Y$. & $1 / \cdots$ & 每/ & $\cdot / F \Delta F$ &.$/ 99$ & ./ATV & $\cdot / r \cdot r$ & $\cdot / V^{\prime} F$ & محل \\
\hline
\end{tabular}


قاعدگى همراه با تخمك گذارى را تحت تاثير قرار

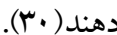

هييومنوره؛ خونريزى قاعدگى در فواصل منظم و و طول)

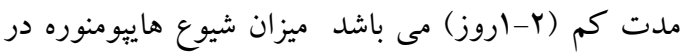

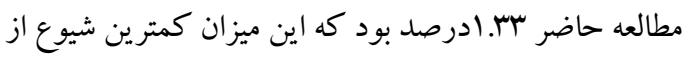

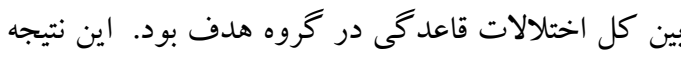
مشابه نتايج مطالعه شاه غيبى و و همكاران

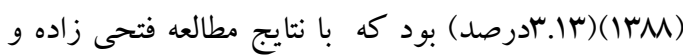

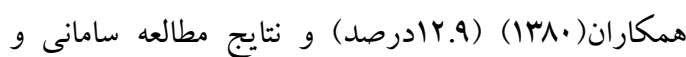

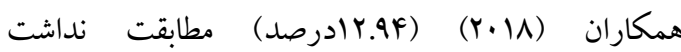
(Y.rF.r. ) موجود مى تواند به دلايل مختلف باشد. در برخى مطالعات،

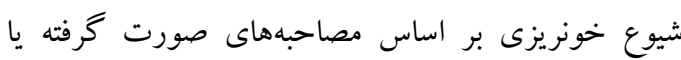

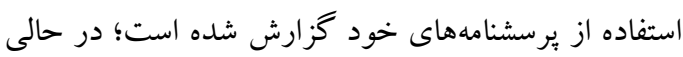
كه در برخى از مطالعات ديخر، از ابزار استاندارد مانند جارت تصويرى ارزيابى خون و يا روش هاى عينى ماند hematin ميزان شيوع ماستالثى در مطالعه حاضر •ا درصد بود كه اين اختلال در مطالعات قبلى به ندرت بررسى شده و آن در

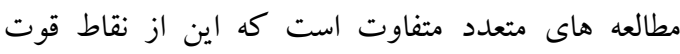

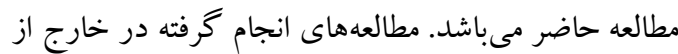

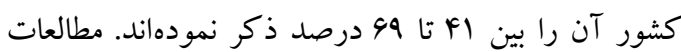
زيادى در ايران در مورد شيوع ماستالزى وجود ندارد،

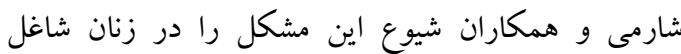

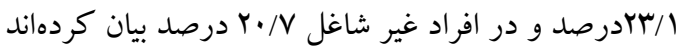
(آ). افراد مبتلا به درد بستان دورماى در معرض خطر

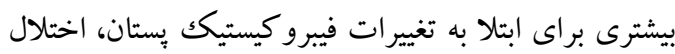
در فعاليتهاى شغلى، اجتماعى و روابط خانو ادگى هستند. اين اختلال به صورت عدم تسلط بر خود در برخوردهاى

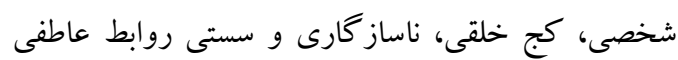
ديده مى شود (rr).
شايع ترين اختلال قاعدگى در اين مطالعه ديسمنوره با شيوع

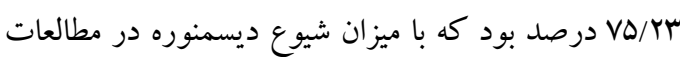
Strinic

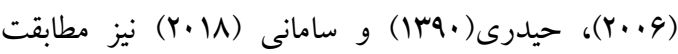

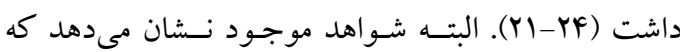
شيوع ديسمنوره در دهلهاى اخير به دليل عوامل محيطى و

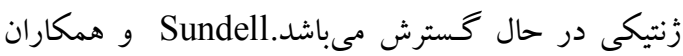

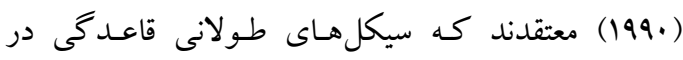
بــروز ديسسمنوره مــؤثر اسـت (Yه). علت ديسمنوره را به

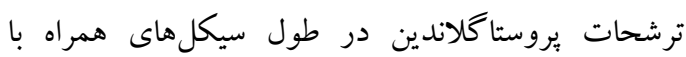

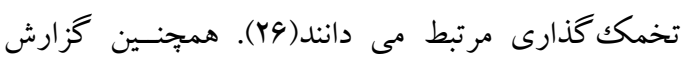

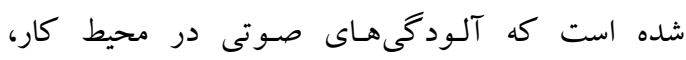

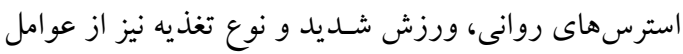

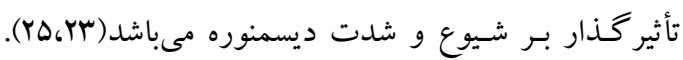

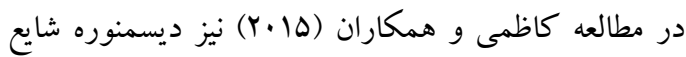

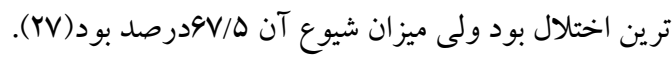

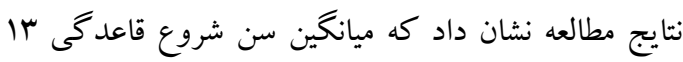

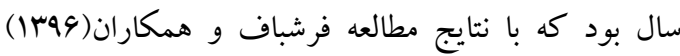

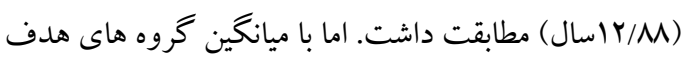

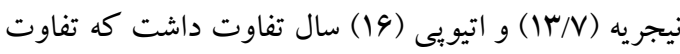

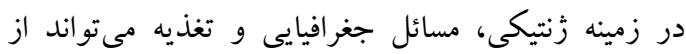
دلايل احتمالى توجيه اين تفاوتها باشد، از سوى دينّ ديخر

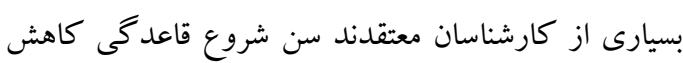

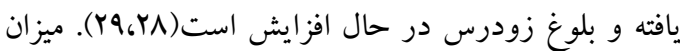
شيوع بلى منوره در مطالعه حاضر ها درصد بود كه تقريبا

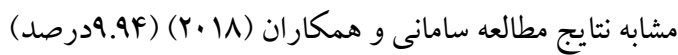

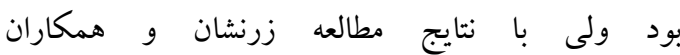

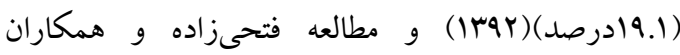

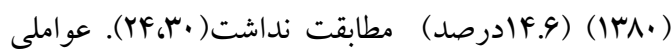
مانند استرس، ورزش در دوره هاى متوسط وBMI در مر

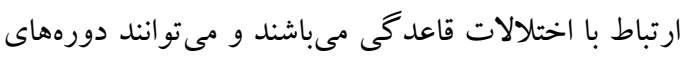


همكاران (IrqV) متفاوت بود كه علت اين تفاوت مى تواند

مربوط به تفاوت سنى كروههاى هدف مى باشد(IV).

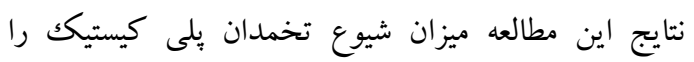

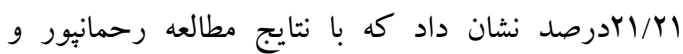

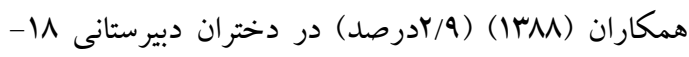

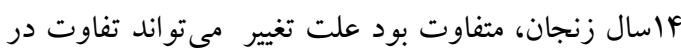
كروه هدف مطالعه و سن كم گروه هدف باشد(1)

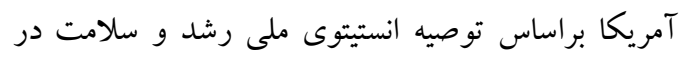

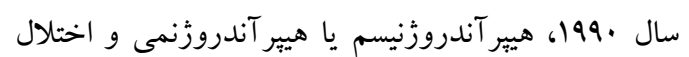
تخمك گذارى در غياب هييريلازى غير كلاسيك آدرنال،

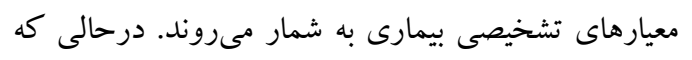

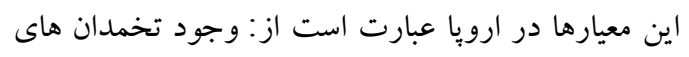

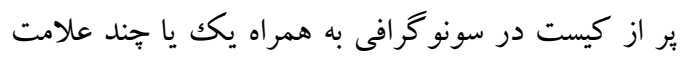

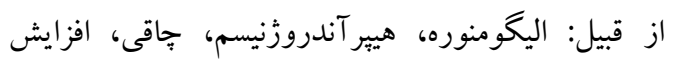
تستوسترون يا LH سرم. به اين دليل شيوع بيمارى در نقاط مختلف دنيا براساس معيارهاى تشخيصى مورد استفاده بين

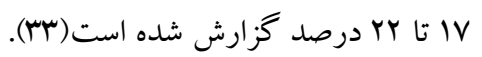

\section{نتيجه كيرى}

نتايج اين مطالعه نشان داد فاكتورهاى سن، BMI و تنيجي وضعيت

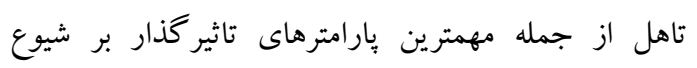

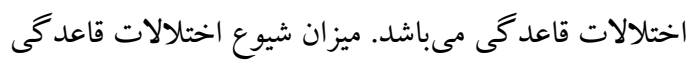

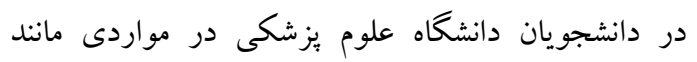

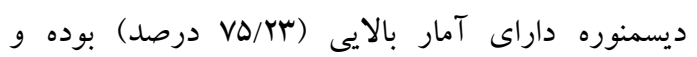

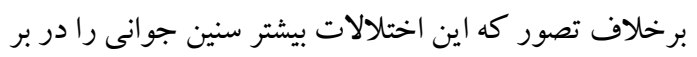

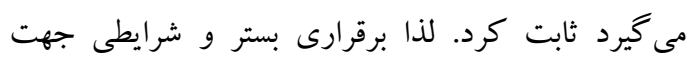

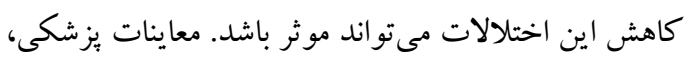

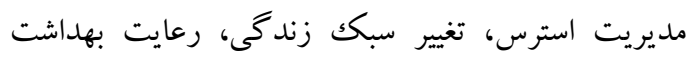

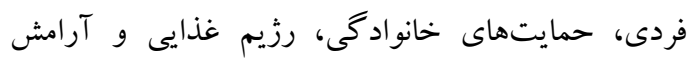
روانى مىتواند باعث كاهش اين اختلالات كردد.

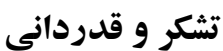

ميزان شيوع اليخومنوره در مطالعه حاضر الدرصد بود كه

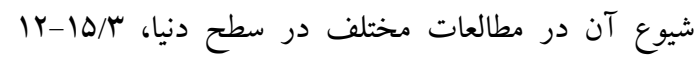
درصد و در ايران حدود هادرصد گز ارش شده است (19). نتايج مطالعه حاضر مشابه نتايج مطالعه شاه غيبى و و دران

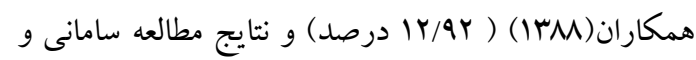

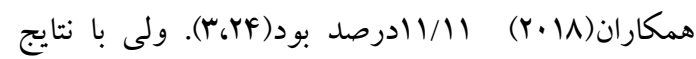

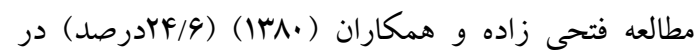

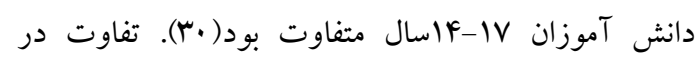
درصد شيوع اليخومنوره مى تواند مربوط به تفاوت در خروه هدف و در نتيجه تفاوت سنى جامعه نمونه و همجنين

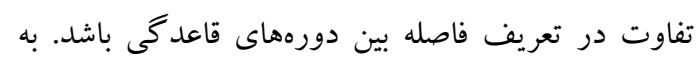

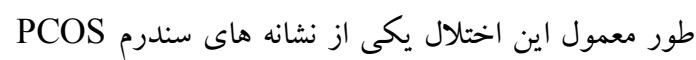

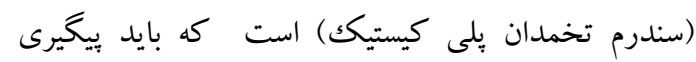
شود) (YV). ميزان شيوع منورازى در مطالعه حاضر سب. ·rدرصد بوده

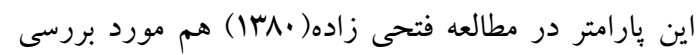

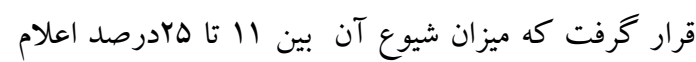

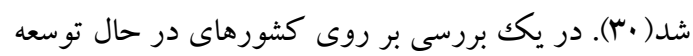
Herlow

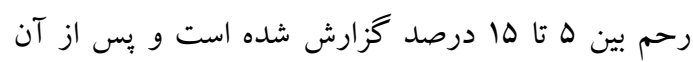

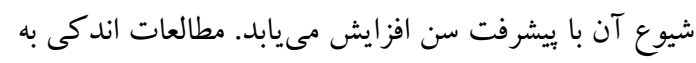
بررسى ميزان خونريزى غيرطبيعى رحم در كشورهاى در

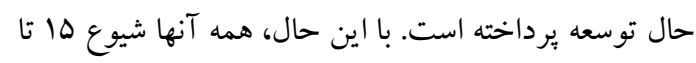

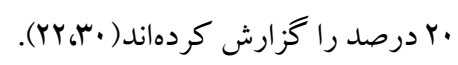

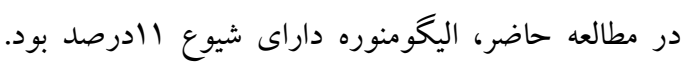

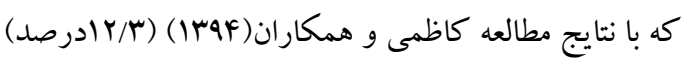

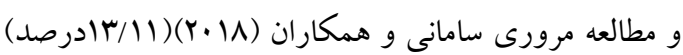

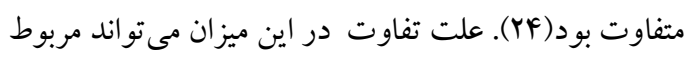
به تفاوت در سن يا تفاوت در تعريف فاصله بين دورههاى قاعدگى باشد(YV).

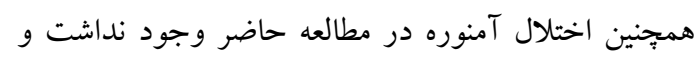

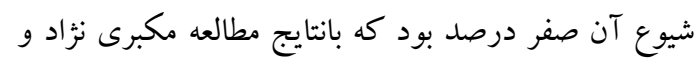




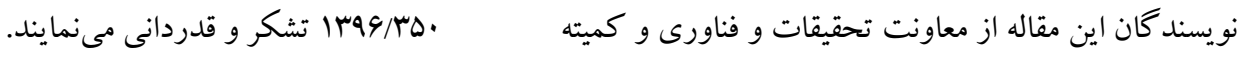

$$
\begin{aligned}
& \text { تحقيقات دانشجويى، يشتيبان مالى اين يروزه با شماره طرح }
\end{aligned}
$$

1. Eunice Olowokere A, Oginni M, Olajubu A, William A, Irinoye O. Menstrual disorders: The implications on health and academic activities of female undergraduates in a federal university in Nigeria. J Nurs Educ.2014;4:126-135.

2. Mohammadi B, Azamian Jazi A , Faramarzi M and Fathollahi Shourabeh. The Effect of Aerobic Exercise Training and Detraining on Some of the Menstrual Disorders in Non-athlete Students in Lorestan Universities. Ofogh-e-Danesh. 2012;18(2):5-12.

3. Shahghaibi SH, Darvishi N, Yousefinejad V, Moghbel N, Shahsavari S. Investigation of the incidence rate of menstrual disorders in 17 and 18 year old high school female students in Sanandaj city. SJKU. 2009;14(3):20-24 Persian).

4. Zarneshan A, Salehzadeh K, Ghorbanian B, Sharabiani S, Shirpour S. The Role of Exercise Indices on Menstrual Dysfunctions inFemale College Athletes. IJOGI. 2013;46(16):20-27 Persian)

5. Nazarpour S, KHazai K. The study of correlation between body image and coping styles with severity of primary dysmenorrhea. Journal of Fundamentals of Mental Health. 2013;4(56):34455 (Persian)

6. Jalili Z, Safizadeh HR, Shamsipoor N. Prevalence of primary dysmenorrhea in college students in Sirjan, Kerman. Payesh. 2005;1(4) ;61-67.( Persian).

7. Teshome Shiferaw M, Wubshet M, Tegabu D. Menstrual problems and associated factors among students of Bahir Dar University, Amhara National Regional State, Ethiopia. PAMJ. 2014;17: $1-9$.

8. Karout N. Prevalence and pattern of menstrual problems and relationship with some factors among Saudi nursing students. J Nurs Educ.2015;5(12):1-8.

9. Olalekan Adebimpe W, Oludele Farinloye E, Ajao Adeleke N. Menstrual Pattern and Disorders and Impact on Quality of Life Among University Students in South-Western Nigeria. JBCRS. 2016; 5(1):27-32.

10. Akhavanakbari P, Ahangar Davoudi SH. Dysmenorrhea Frequency and Severity and Its Related Factors in Students of Ardabil University of Medical Science. j.h.2010;1(3):41-47 (Persian)

11. Soltani F, Shobeiri F. Menstrual Patterns and its Disorders in High School Girls. IJOGI .2011; 1(14): 28-33(Persian) .

12. Delara M, Borzuei H, Montazeri A. Premenstrual Disorders: Prevalence and Associated Factors in a Sample of Iranian Adolescents. Iran Red Crescent Med J. 2013;15(8):695-700.

13. Yashwant Aher J, Mahendra Rajole K. A Cross-Sectional Study of Prevalence of Dysmenorrhea among Adolescent Girls. Sch. J. App. Med. Sci. 2016;4(9):3421-3423.

14. Hui Cheng SH, Shih CH, Kuang Yang Y, Chen K, Chang Y, Yang Y. Factors associated with premenstrual syndrome -A survey of new female university students. KJMS. 2013; 29 (2):100-5.

15. Farokh-Eslamlou H, Nabilou B, Oshnoee S, Akbari E. The Prevalence Of Premenstrual Syndrome and ITS Associated Factors Among Medical Students Of Urmia University Of Medical Sciences. Urmia Med J.2013; 24(9):702-710 (Persian).

16. Falahat F, Tavakkoli M, Mokaberinejad R, Ayati S, Feyzabadi Z, Natural Treatment of Oligomenorrhea Based on Iranian Medicinea. IJOGI.2018; 21:55-66. (Persian)

17. Mokaberinejad R, Zafarqandi $\mathrm{N}, \mathrm{A}$ review of the causes and effects of amenorrhea (reticulum) in traditional Iranian medicine. ACECR. 2018; 3(1):19-30 (Persian)

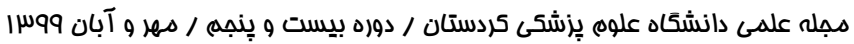


18. Rahmanpour H, Heidari R, Mousavinasab SN, Sharifi F, Fekri S. The Prevalence of

Polycystic Ovarian Syndrome in 14-18 year old girls of Zanjan High Schools. J Adv Med Biomed Res. 2009;17(67): 79-88 (Persian).

19. Ahmadnia E, Maleki A, Moosavinasab N. Menstrual cycle pattern, its related disorders and associated factors in students of Zanjan, Iran. Qom Univ Med Sci J.2014;8(2):51-58. (Persian).

20. Torkmannejad M, Mohebbi Dehnavi Z, Rad M, mohebbi dehnavi Z. Association Between Menstrual Disorders and Obesity-Related Anthropometric Indices in Female High School Students: A Cross-Sectional Study. J SCHOOL HEALTH, 2018; 5(2):1-8.

21. Strinic T, Bukovic D, Pavelic L, Fajdic J, Herman I, Stipic I. Anthropological and clinical characteristics in adolescent women with dysmenorrhea. Coll Antropol. 2003; 27(2):707-11.

22. Sibn D, Herlow. A longitudinal study of risk factors for the occurrence duration and severity of menstruan cramps in a cohort college women. BJOG. 2006;103:1134-1142 .

23. Haidari F, Akrami A, Sarhadi M, Mohammad Shahi M. Prevalence and Severity of Primary Dysmenorrhea and its Relation to Anthropometric Parameters . Hayat. 2011;17(1):70-77.

24. Omani Samani R, Almasi Hashiani A, Razavi M, Vesali S, Rezaeinejad M, Maroufizadeh S . The prevalence of menstrual disorders in Iran: A systematic review and meta-analysis. IJRM; 2018; 16(11):665-678.

25. Sundell G, Milsom I, Andersch B. Factors influencing the prevalence and severity of dysmenorrhoea in young women. Br J Obstet Gynaecol. 1990; 97(7):588-94.

26. Rostami Dovom M, Ramezani Tehrani F, Farahmand M, Hashemi S, Rezaee N, Azizi F. Prevalence of Menstrual Disorders and its Related Factors in 18-45 year-old Iranian Women in Four Selected Provinces. Hakim Health Sys Res. 2014;17(3):192- 199.

27. Kazemi jaliseh H, Ramezani Tehrani F, Behboudi-Gandevani S, Khalili D2, Hosseinpanah F, Azizi F. The Prevalence of Menstrual Disorders in Reproductive Aged Women and its Related Factors. IJEM. 2015;17(2):105-112 .

28. Farshbaf Manei Sefat F, Abolghasemi A, Barahmand U, Hajloo N, A Survey of Menstruation Pattern and Prevalence of Dysmenorrhea in Ardabil Second High School Students. IJE 2017;13(3):235-243.

29. Kordi M, Mohamadirizi S, Shakeri M. The Survey of menarche, dysmenorrhea and menstruation characteristics menstruation in Mashhad's high school girls in the year of 2010; IJOGI. 2011;15:10-18.

30. Fathizadeh N, Faraji L, Khodakarami N, Nahidi F. Investigating of menstruation disorder in the beginning of girls puberty(14-17 years old) in Tehran selecting schools. J Shahrekord Univ Med Sci. 2001;3(1):41-46 (Persian).

31. Sharami S, Sobhani A, Asgharnia M, Shabaani M. Prevalence of Cyclic Mastalgia and It's Relation With Age, Marriage and Employment Outside the House . jour guilan uni med sci. 2000; 9(33):111-116.

32. Fakhravar S, Bahrami N, Olfati F, Effect of individual counseling on pain quality in the women with cyclic mastalgia: a clinical trial. JQUMS. 2018: 22(4):22-30

33. Naderi T. AkbarzadehM. Dabbaghmanesh MH. Tabatabaei HR. Prevalence of various phenotypes of polycystic ovarian syndrome among high school girls of Shiraz .JQUMS.2012;15(4):60-67.

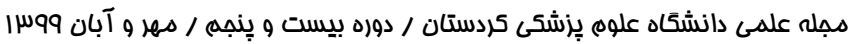

